\title{
Perampasan Hak dan Kesejahteraan Petani oleh Tengkulak di Kabupaten Aceh Barat
}

\author{
Rudi Andika ${ }^{1}$, Marzuki ${ }^{2}$, Rahmad Halomoan Lubis ${ }^{3}$, Cut Vely Muliyana ${ }^{4}$, Safrida $^{5}$ \\ ${ }^{1}$ Jurusan Ilmu Administrasi Negara, Universitas Teuku Umar, Indonesia \\ ${ }^{2} J u r u s a n$ Ilmu Administrasi Negara, Universitas Teuku Umar, Indonesia \\ ${ }^{3}$ Jurusan Ilmu Komunikasi, Universitas Teuku Umar, Indonesia \\ ${ }^{4}$ Jurusan Ilmu Administrasi Negara, Universitas Teuku Umar, Indonesia \\ ${ }_{5}^{5}$ Jurusan Ilmu Administrasi Negara Universitas Teuku Umar, Indonesia
}

\begin{tabular}{l} 
ARTICLE INFORMATION \\
\hline Received: September 23, 2020 \\
Revised: November 01, 2020 \\
Accepted: November 10, 2020 \\
Available online: November 14, 2020 \\
KEYWORDS \\
\hline Farmer, Holdup, Middlemen, Goverment \\
CORRESPONDENCE \\
\hline
\end{tabular}

Phone: +6285260799939

E-mail: safrida1290@utu.ac.id

\begin{abstract}
A B S T R A C T
Agriculture is one of the main centers as source of livelihood for the people in west aceh regency, this can be seen from the yields of farmers which are increasing every year. However, the increase in yields is inversely proportional to the welfare of the west aceh farmers, due to the influence of price manipulation by middlemen. This study aims to examine the role and supervision of the government in protecting the rights of farmers from middlemen in west Aceh district. The method used in this research is qualitative with a variety of secondary data analysis techniques and used scientific narrative review data analysis techniques. The results show that discrimination against farmer by middlemen was indeed common in west Aceh. The role of the west Aceh government in overcoming this problem is by providing education, issuing policies on program for providing business capital to farmers. Meanwhile, the supervision that the goverment faces is in the form of a minumun level of public response to policies that have been regulated by the government and a lack of trust from the peasant community in the government
\end{abstract}

\section{PENDAHULUAN}

Indonesia merupakan salah satu negara dengan kekayaan sumber daya alam yang melimpah, hal tersebut dibuktkan dengan keberadaan lahan yang subur, hamparan tanah luas, hutan lebat, sungai dengan air yang mengalir disepanjang tahun (Aminah, 2017). Kekayaan sumber daya alam yang melimpah tersebut menjadikan banyak masyarakat Indonesia berprofesi sebagai petani. Jumlah petani yang tersebar di 514 Kabupaten/Kota di Indonesia saat ini mencapai 39 juta jiwa atau 34\% dari total penduduk secara keseluruhan (Rahmadani, 2017).

Salah satu Kabupatennya adalah Aceh Barat, sebagian besar penduduknya juga menggantungkan mata pencaharian disektor pertanian (aceh.antaranews.com). Sepanjang sejarah, kelompok petani dalam usaha pertaniannya tidak pernah menjadi kelompok "the winner" bargaining power and bargaining position dalam menghadapi kondisi alam yang keras, mulai dari struktur kekuasaan ekonomi dan politiknya yang menindas, sistem pengetahuan dan teknologi yang tidak memihak (Hardika, 2011). Sejalan dengan pendapat (Syaifuddin, 2016). Keadaan yang tidak mendukung terhadap petani tersebut akan membuat petani tidak bisa melepaskan diri dari jeratan kemiskinan dan pada akhirnya petani tetap menjadi golongan yang gagal memperbaiki kehidupan ekonominya. Keadaan yang demikian berbanding terbalik dengan harapan petani yang menginginkan kehidupan yang layak seperti masyarakat lain pada umumnya,. hal tersebut https://doi.org/10.35308/jpp.v6i2.2608
Senada dengan pemikiran (Deo Leko Pudaka, 2018) yang Menyatakan bahwa sebenarnya petani menginginkan kesejahteraan dan kelayakan dari hasil pertaniannya. petani Aceh Barat salah satunya.

Permasalahan itu tampak juga ketika sistem ekonomi dan politik tidak memihak kepada mereka para petani kecil. Bahkan yang sering terjadi para petani menjadi objek segala kebijakan dari atas yang tidak adil. (Hutabarat, 2013) melihat kesuraman lain yang dilanda oleh petani adalah terjadinya fluktasi harga hasil pertanian yang berlebihan, sedangkan (Hawa, 2003) melihat kesuraman utama yang dihadapi petani adalah minimnya pengetahuan petani dalam mengelola hasil pertanian dengan baik, (Nugroho, 2001) berpendapat bahwa tengkulaklah yang menjadi problema krusial dalam proses jual beli hasil pertanian petani. (Iwan Zaenul Fuad, Aenurofik, 2015) mendefiniskan Tengkulak sebagai suatu pihak yang memiliki sejumlah modal untuk membeli hasil dari suatu usaha pertanian.

Berdasarkan Undang-Undang Republik Indonesia Nomor 19 Tahun 2013 tentang Perlindungan dan Pemberdayaan Petani pasal 1 ayat 1 menjelaskan bahwa perlindungan petani adalah segala upaya untuk membantu Petani dalam menghadapi permasalahan kesulitan memperoleh prasarana dan sarana produksi, kepastian usaha, risiko harga, kegagalan panen, praktik ekonomi biaya tingg dan perubahan iklim. Pada pasal 
22 ayat 2 menjelaskan bahwa memberikan jaminan pemasaran hasil pertanian kepada petani yang melaksanakan usaha tani sebagai program pemerintah (Perundangan. pertanian.go.id).

Namun, implementasinya tidak berjalan sesuai dengan harapan, terdapat berbagai permasalahan di lapangan mengenai harga daya beli hasil pertanian dalam masyarakat, permasalahan tersebut muncul karena adanya permainan monopoli harga yang diinisiasi oleh tengkulak. (Musyarofah, Suharso, \& Kartini, 2017) berpendapat bahwa permainan monopoli harga dilakukan oleh tengkulak dengan mempengaruhi petani untuk menjual hasil panennya dengan harga yang sangat rendah kemudian tengkulak menjual nya dengan harga yang relatif tinggi kepada perusahaan atau grosir lain yang lebih besar darinya.

Permasalahan di atas juga terjadi di kalangan petani Kabupaten Aceh Barat yang sering mengalami perubahan (fluktasi) harga hasil pertanian yang dilakukan oleh tengkulak, tengkulak dianggap memiliki peran negatif bagi petani (Azizah, 2018), salah satu acuan negatifnya adalah rendahnya harga beli yang ditawarkan oleh tangkulak daripada harga yang telah diterapkan oleh pemerintah sehingga mata pencarian sebagai petani selama ini belum bisa meningkatkan perekonomian ataupun kesejahteraan masyarakat tani di Kabupaten Aceh Barat, seperti diberitakan di (Tribunnews.com, 2019) harga GKP diawal panen pada awal beberapa tahun belakangan, berkisar antara Rp 4.700 hingga Rp 4.800 per kilogram (kg). Namun, semakin hari sejumlah harga semakin drop sampai pada kisaran Rp 4.500 sampai Rp 4.650 per kg. Berdasarkan hal tersebut dapat disimpulkan bahwa setiap musim panen masyarakat, harga padi petani menjadi sangat murah, sedangkan harga beras di pasar relatif tinggi dijual kepada masyarakat. Disinilah Perlu peran pemerintah dalam upaya memberikan perlindungan hak terhadap petani serta memberantas penyelewengan harga oleh para tengkulak yang tidak bertanggung jawab sehingga perkonomian petani setiap tahunnya tidak meningkat.

Berdasarkan uraian yang telah dipaparkan maka penulis merasa tertarik untuk meneliti tentang "Perampasan Hak dan Kesejahteraan Petani oleh Tengkulak di Kabupaten Aceh Barat”. Adapun yang menjadi tujuan penulis dalam melakukan penelitian ini adalah untuk melihat bagaimana peran pemerintah dalam melindungi hak petani dari tengkulak di Kabupaten Aceh Barat serta mengetahui apa yang menjadi hambatan pemerintah dalam melindungi hak petani dari tengkulak.

\section{METODE}

Metode penelitian yang digunakan adalah kualitatif dengan teknik pengumpulan data secara sekunder melalui studi literatur e-library, dokumentasi, pengumpulan data melalui website media sosial. Data-data yang dikumpulkan merupakan data sekunder yang diperoleh dari google scholar (Jurnal-jurnal terakreditasi) dalam rentang waktu 10 tahun terakhir, yaitu 2010-2020. Kemudian data-data yang sudah dikumpulkan akan disimpan ke dalam software Mendeley App untuk memudahkan analisis data. (S. Aminah dan Roikan, 2019). menjelaskan data sekunder merupakan data yang dikumpulkan dari tangan kedua (peneliti lain) atau dari sumber-sumber lain yang telah tersedia sebelum penelitian dilakukan serta digunakan sebagai pelengkap dari data primer.

Namun dalam penelitian ini yang menjadi data primernya adalah data-data sekunder dikarenakan tidak adanya pengumpulan data secara langsung kelapangan. Data skunder juga diperoleh dari hasil narative review. Menurut Kitchenham dalam (Siswanto, 2010) system review adalah teknik penelitian dengan mengamati, menilai dan interpretasi terhadap semua hasil penelitian yang telah diteliti sebelumnya serta berhubungan dengan permasalahan penelitian tertentu dan suatu topik tertentu.

Teknik analisis data yang digunakan dalam penelitian ini adalah dengan menggunakan langkah-langkah seperti yang dikemukakan oleh Burhan Bungin dalam (Andika dkk, 2019) yaitu sebagai berikut :

a. Pengumpulan Data (Data Collection). pengumpulan data merupakan bagian integral dari kegiatan analisis data. Kegiatan pengumpulan data pada penelitian ini adalah dengan menggunakan wawancara dan studi dokumentasi.

b. Reduksi Data (Data Reduction). Reduksi dilakukan sejak pengumpulan data dimulai dengan membuat ringkasan, mengkode, menelusur tema, membuat gugus-gugus, menulis memo dan sebagainya dengan maksud menyisihkan data/informasi yang tidak relevan.

c. Display Data. Display data adalah pendeskripsian sekumpulan informasi tersusun yang memberikan kemungkinan adanya penarikan kesimpulan dan pengambilan tindakan. Penyajian data kualitatif disajikan dalam bentuk teks naratif. Penyajiannya juga dapat berbentuk matrik, diagram, tabel dan bagan.

d. Verifikasi dan Penegasan Kesimpulan (Conclution Drawing and Verification) Merupakan kegiatan akhir dari analisis data. Penarikan kesimpulan berupa kegiatan interpretasi, yaitu menemukan makna data yang telah disajikan

\section{HASIL DAN PEMBAHASAN}

\section{Perampasan Hak dan Kesejahteraan Petani di Kabupaten Aceh Barat}

Menurut Thomas Habbes dalam (Iwan Zaenul Fuad, Aenurofik, 2015) Keserakahan manusia dalam memperebutkan sumber daya untuk kepentingannya sendiri jelas terlihat di dalam kehidupan perekonomian liberal yang menjunjung tinggi kebebasan dalam berusaha. $\mathrm{N}$ amun, pemikiran seperti ini sangatlah memojokkan pihak-pihak tertentu karena pada umumnya hanya pihak yang kuatlah yang akan memenangkan persaingan usaha. Tentu hal demikian tidak diinginkan karena akan berdampak pada ketidakseimbangan perekonomian masyarakat dalam kehidupan sehari-hari. Sifat keserakahan manusia dalam meraup keuntungan dari kekayaan alam ini bisa dilihat dalam proses bentuk jual beli hasil usaha dari petani Aceh Barat dengan para tengkulak yang mengakibatkan terjadinya kesenjangan sosial.

Hasil pertanian di Kabupaten Aceh Barat setiap tahunnya terus mengalami peningkatan. Salah satu peningkatannya adalah pada sektor tanaman padi. Berikut disajikan pada tabel 1. data jumlah peningkatan hasil pertanian padi di Kabupaten Aceh Barat. 
Table l. jumlah peningkatan hasil pertanian padi Aceh Barat

\begin{tabular}{ccc}
\hline Tahun & Jumlah hasil & Luas lahan \\
\hline 2017 & 5,7 Ton & 1 Hektar \\
2018 & 5.9 Ton & 1 Hektar \\
2019 & 8,0 Ton & 1 Hektar \\
\hline
\end{tabular}

Sumber: acehbarat.go.id

Seharusnya dengan kenaikan tersebut mampu membuat petani Aceh Barat keluar dari lingkaran setan kemiskinan dan dapat menuju kepada kesejahteraan. Namun, dikutip dari (Kompas.com) kemiskinan terhadap petani di Aceh Barat masih dalam kategori tinggi, seperti masyarakat tani Kecamatan Woyla di Desa Gempa Raya, dari 90 KK yang menetap di sana 75 KK diantaranya masih hidup di bawah garis kemiskinan.

Menurut (Nugroho, 2001), salah satu faktor yang menyebabkan permasalahan tersebut terjadi dikarenakan adanya diskriminasi petani yang dilakukan oleh tengkulak, salah satunya yang paling berpengaruh adalah penyelewengan harga beli hasil tani oleh tengkulak. Pada dasarnya tengkulak memiliki peran penting dalam hal sebagai pengontrol ekonomi petani. Sebagaimana yang dijelaskan oleh (Asromi, 2003) mengenai bagaimana sebenarnya peran dari tengkulak dalam upaya meningkatkan ekonomi sebagai salah satu roda penggerak perekonomian masyarakat di wilayah setempat. Akan tetapi, peran tersebut seringkali disalahgunakan oleh tengkulak, tengkulak memainkan harga beli hasil tani dengan harga yang relatif rendah kemudian menjualnya kembali kepada konsumen dengan harga yang lebih tinggi.

Adanya sifat ketergantungan juga menjadi penyebab terjadinya kemiskinan bagi petani Aceh Barat, sifat ketergantungan tersebut terjadi karena adanya pola kebiasaan yang terus dilakukan oleh petani sehingga alur penjualan hasil panen melalui tengkulak setiap tahunnya masih terus terjadi meskipun harga yang ditawarkan terbilang rendah. Hal tersebut selaras dengan pendapat yang dikemukakan oleh (Russel, 2015) bahwa dengan hadirnya tengkulak dalam sistem pertanian mengakibatkan terjadinya ketergantungan antara petani terhadap tengkulak karena petani tidak memiliki pengetahuan seperti yang dimiliki oleh tengkulak dan hal tersebut juga berlaku bagi petani yang ada di Aceh Barat.

\section{Peran Pemerintah dalam Melindungi Hak Petani Sebagai Upaya Peningkatan Perekonomian Masyarakat.}

Permasalahan distribusi harga hasil pertanian di Aceh Barat masih kerap terjadi. Dalam hal ini, pemerintah harus memberikan rasa simpati kepada masyarakat kelas bawah khususnya yang berprofesi sebagai petani dengan mengedepankan peranan aktif dari Pemerintah dalam mengatasi segala permasalahan dan diskriminasi yang dialami oleh masyarakat petani. Seperti peran Pemerintah DKI Jakarta yang disebutkan pada jurnal (Rani, Taufikurahman, \& Lenggono, 2019) yang mengimplementasikan perannya dalam menangani permasalahan penetapan harga di sektor pertanian pada cabai merah keriting, hal yang dilakukan berupa tindakan:

1. Kerjasama dan pengontrolan harga di setiap saat secara rutin, sistematis, terevaluasi dengan lembaga-lembaga yang berwenang, tujuannya agar semua elemen terkait baik itu petani, agen serta konsumen dapat difungsikan sebagai mana mestinya dan dapat meminimalisir pihak atau komponen rantai pemasok melakukan permainan yang dapat merugikan komponen lainnya (petani).

2. Konsisten dengan pengendalian harga pangan di daerah oleh pemerintah.

3. Kerjasama di sektor sumber cabai dalam rangka menjamin stabilitas harga bahan pokok makanan.

Bersamaan dengan peran Pemerintah Aceh Barat dalam upaya memberikan perlindungan terhadap petani dari tengkulak sudah dilakukan, seperti yang dikutip oleh penulis dari laman (aceh.antaranews.com, 2019) bahwasanya pemerintah Aceh Barat sudah memberikan penyuluhan kepada masyarakat yang membutuhkan modal usaha agar tidak mengambil pinjaman yang ditawarkan oleh tengkulak karena akan mengakibatkan terbebannya petani dengan bunga pinjaman yang cukup mahal ditambah lagi kesejahteraan petani berkurang dikarenakan petani harus menjual hasil tani kepada tengkulak dengan harga yang murah. Dikutip dari laman (harian.aceh.go.id, 2020), bentuk upaya lainnya yang diinisiasikan oleh Pemerintah Aceh Barat agar petani terhindar dari jeratan tengkulak adalah dengan mengeluarkan kebijakan berupa program pemberdayaan ekonomi dengan memberikan modal usaha kepada masyarakat di setiap desa, modal yang dialokasikan yakni uang tunai mulai dari 5 juta sampai 15 juta/KK

\section{Hambatan Pemerintah dalam Melindungi Hak Petani dari Tengkulak.}

Proses terealisasikannya upaya yang dilakukan Pemerintah Kabupaten Aceh Barat masih terdapat beberapa kendala baik di tingkat Kabupaten, Kecamatan sampai ke tingkat Pemerintah Desa. Adapun kendala-kendala yang umum terjadi (Bahri, 2019) antara lain kelompok yang memiliki kepentingan, mutu sumber daya manusia dan perencanaan yang tidak berjalan sesuai dengan yang diharapkan. Sebagai contoh kasusnya adalah hambatan yang dialami oleh Pemerintah Daerah Mojokerto dalam upaya meningkatan kesejahteraan petani di Desa Kaligoro yakni berupa minimnya pemberian training edukasi kepada orang-orang yang berkecimpung dalam mensosialisasikan hal-hal terkait pertanian kepada masyarakat, hambatan lainnya adalah kurangnya respon dari masyarakat untuk ikut berkontribusi dalam upaya penyuksesan program-program yang diinisiasikan oleh pemerintah, sehingga implementasinya tidak berjalan secara optimal (Arif, 2013).

Begitu pula hambatan yang dirasakan oleh Pemerintah Kabupaten Aceh Barat seperti dilansir dalam (harian.aceh.go.id,2020) yakni:

1. Minimnya tingkat responsif (less responsive) masyarakat petani terhadap kebijakan yang diberikan oleh pemerintah. Banyak masyarakat yang kurang berpastisipasi terhadap program-pogram yang diusulkan pemerintah untuk menanggulangi tengkulak

2. Kurangnya rasa kepercayaan (less trust) masyarakat petani terhadap pemerintah. Dikarenakan petani masih terikat persepsi akan kemudahan penjualan hasil panen kepada tengkulak, hal demikian terjadi akibat minimnya tingkat pendidikan yang dimiliki petani. 


\section{Solusi dalam Melindungi Hak Petani dari Tengkulak}

Berdasarkan segala pokok pangkal permasalahan mengenai tengkulak maka penulis memberikan beberapa solusi alternatif yang bertujuan untuk menanggulangi atau mengurangi tingginya pengaruh para tengkulak yang mendominasi dalam meraup keuntungan lebih pada aspek harga beli hasil pertanian dari petani. Alternatif yang dicetuskan merupakan rumusan dari hasil studi literatur yang dilakukan oleh penulis. Alternatif tersebut adalah sebagai berikut:

1. Pembetukan Website Hasil Tani

Penggunaan website merupakan salah satu bagian dari teknologi yang dapat mengurangi permasalahan di bidang pertanian, sejalan dengan pendapat (Heliyon, 2020) yang mengatakan bahwa "Dalam bidang pertanian, pemakaian teknologi merupakan suatu usaha yang sangat menjanjikan dalam rangka menjawab tantangan masa depan untuk menciptakan kesejahteraan".

Adapun mekanisme pembentukan website yang penulis usulkan adalah sebagai berikut:

a. Website tersebut dikelola oleh Pemerintah Kabupaten

b. Aceh Barat.

c. Pemerintah menginput jumlah besaran hasil panen pada setiap musim panen tiba.

d. Adanya pembuatan fitur website yang berhubungan dengan penetapan harga hasil pertanian agar masyarakat dapat melihat berapa harga hasil pertanian yang ditetapkan oleh pemerintah sesungguhnya, sehingga tidak lagi ditipu oleh tengkulak-tengkulak yang ingin mengambil keuntungan.

e. Memberikan ruang komunikasi dua arah baik pemerintah, tim pengawas, konsumen dan petani.

f. Adanya tim khusus yang dibuat oleh Pemerintah Aceh Barat untuk mensosialisasikan tata cara penggunaan website kepada petani.

\section{Pengawasan Rantai Tata Niaga Hasil Tani}

Pengawasan tersebut dilakukan oleh Dinas Perindustrian, Perdagangan dan Koperasi (DISPERINDAGKOP) Kabupaten Aceh Barat. Mekanisme yang penulis tawarkan adalah:

a. Membagi tim pengawasan kesetiap Kecamatan yang ada di Aceh Barat (12 kecamatan), tiap-tiap tim yang sudah dibagi harus mengontrol dengan detail terhadap tengkulaktengkulak yang bermain di desa-desa.

b. Membentuk posko atau penampung aspirasi dan keluhan dari masyarakat petani.

c. Rutin melakukan evaluasi oleh tim.

Solusi yang diajukan oleh penulis tersebut diharapkan mampu memberikan jalan keluar terhadap keresahan para petani. Sehingga hak dan kesejahteraan petani tidak lagi dirampas oleh tengkulak yang hanya ingin mengambil keutungan lebih banyak

\section{KESIMPULAN}

Kasus perampasan hak petani Aceh Barat oleh tengkulak terjadi karena kurangnya pengetahuan yang dimiliki petani tentang masalah penetapan harga pangan, ketergantungan petani kepada tengkulak juga menjadi salah penyebab perampasan hak petani terus terjadi. Peran pemerintah Aceh
Barat sebagai pelindung masyarakat tani dari tengkulak sudah dilakukan, diantaranya dengan memberikan edukasi, mengeluarkan kebijakan program pemberian modal usaha kepada petani dengan tujuan dapat teruntuhkannya jeratan tengkulak pada petani Aceh Barat. Hambatan yang pemerintah hadapi dalam memberantas jeratan tengkulak berupa minimnya tingkat responsif (less responsive) masyarakat petani terhadap kebijakan yang telah diregulasikan oleh pemerintah serta masih Kurangnya rasa kepercayaan (less trust) masyarakat petani terhadap pemerintah.

Dalam melakukan penelitian ini penulis juga masih mempunyai keterbatasan-keterbatasan, keterbatasan tersebut terjadi karena pandemi covid-19 yang membuat peneliti tidak bisa leluasa secara bebas mendapatkan data-data yang spesifik. Namun kendati demikian, penulis berusaha semaksimal mungkin dalam menutupi keterbatasan tersebut dengan melakukan penyesuaian keadaan untuk mendapatkan data penelitian yang akurat meskipun tidak turun lapangan langsung.

\section{REFERENSI}

Aminah. (2017). Tambang Rakyat, Berkah Atau Musibah? (Studi Tentang Tambang Emas Rakyat Di Gunung Ujeun Kabupaten Aceh Ajaya). Jurnal Public Policy, 39-48.

Aminah, S., \& Roikan. (2019). Pengantar Metode Penelitian Kualitatif Ilmu Politik. Jakarta Timur: Prenademia Group.

Asromi, Y. (2003). Peran Pedagang Pengumpul Hasil Bumi Dalam Pemasaran Lada Dan Kopi. Depok: Universitas Indonesia.

Bahri, B. A., \& W. P. (2019). Peran Pemerintah Desa Terhadap Pembangunan Kewirausahaan Pertanian Sebagai Sarana Untuk Meningkatkan Kesejahteraan Masyarakat. Jurnal Penelitian Agrisamudera, 82-94.

Fuad, I. Z., A. A., \& A. R. (2015). Belenggu Tengkulak Atas Petani Pembudidaya Lele : Relasi Patron Klien Budidaya Lele Di Wonotunggal Jawa Tengah. Hukum Islam IAIN Pekalongan, 88-89.

Hardika. (2011). Transformasi Pola Matapencaharian Petani : Strategi Dan Perilaku Belajar Petani Di Kawasan Transisi Dalam Mengembangkan Kehidupan Pendidikan Luar Sekolah. Ilmu Pendidikan UNM, 90.

Harian.Aceh.Go.Id. (2020). Modal Usaha 15 Juta, Kata Bupati : Agar Rakyat Tak Terjerat Rentenir. Aceh Barat.

Hawa. (2003). Studi Kesiapan Petani Untuk Melaksanakan Pengelolaan Usaha Tani Melalui Pendidikan Ekonomi Sebagai Perusahaan Pertanian . Jurnal Ilmu-Ilmu Sosial.

Heliyon. (2020). Character Strenghts And Sustanable Technology Adoption By Smallholder Farmer. Jurnal Tel-Aviv University.

Hutabarat. (2013). Analisis Faktor-Faktor Yang Mempengaruhi Petani Dalam Penjualan Padi Ke Tengkulak Di Kecamatan Jatilawang Kabupaten Banyumas. Agritech, 87-104.

Iskandar. (2009). Pengantar Ilmu Kualitatif. Jakarta: Gaung Persda Press.

Kompas.Com. (2016). Potret Kemiskinan Warga Pedalaman Aceh Barat. Aceh Barat.

Laili, F. S., R. H., \& N. F. (2014). Pemberdayaan Petani Dalam Meningkatkan Ketahanan Pangan. Administration Public (JAP), 147-153. 
Musyarofah, M. S., \& Kartini. (2017). Preferensi Petani Dalam Penjualan Gabah Pasca Panen Di Desa Sumur Mati Kecamatan Samberasih Kabupaten Probolinggo . Pendidikan Ekonomi, 81.

Nugroho. (2001). Negara Pasar Dan Keadilan Sosial. Yogyakarta: Pustaka Pelajar.

Nurul, A. E. (2018). Peran Positif Tengkulak Dalam Pemasaran Buah Manggis Petani : Studi Jaringan Sosial Tengkulak Di Desa Karacak, Kecamatan Lewilang Kabupaten Bogor . Indonesian Journal Of Sociology And Education Policy, 80-102.

Pudaka, D. L., Rusdanti, \& E. P. (2018). Effeciency Analysis Of Rice Production And Farmer's In Come In Sangah Tamila District Landak Regency. Ecoconomic Education JEE, 31-38.

Ramadani. (2017). Analisis Struktur Agensi Sumber Pendapatan Ganda Petani Miskin Sawah Nagar Batipuah Baruah Kabupaten Tanah Datar. Ilmu Sosial Mamagan, 11-12.

Rani, N. M., M. T., \& Lenggono, P. S. (2019). Analalisis Rantai Pasok Cabai Merah Keriting (Capsium Annum L) Di DKI JAKARTA (Studi Kasus : Pasar Induk Keramat Jati). Economic Resource, 15-26.

Ronna, A., A. P., \& Y. A. (2013). Peran Pemerintah Daerah Kabupaten Mojokerto dalam Meningkatkan Kesejahteraan Petani di Desa Kaligoro Kecamatan Kuterojo Kabupaten Mojokerto. Jurnal Pendidikan Kewarganegaraan UNM.

Susan, R. (2015). Middleman and Moneylanding : Relation Of Exchange In A Highland Philiphine Economic. Antroplogy Research, 43.

Syarifuddin. (2016). Kajian Sosial Ekonomi Yang Memepengaruhi Kemiskinan Petani (Studi Kasus Kecamatan Payung Kabupaten Karo). Agribisnis Sumatera Utara.

Tribunnews.Com. (2019). Harga Gabah Di Abdya Anjlok. Aceh Barat Daya.

Aceh.Antaranews.com. (2015). Pertanian Sumber Ekonomi Utama Aceh Barat. Aceh Barat.

Aceh.Antaranews.Com. (2019). Harga Karet Tingkat Petani di Aceh Barat Masih Rendah Rp. 7000/Kg. Aceh Barat. 